\title{
Anti-HER-2 engineering antibody ChA21 inhibits growth and induces apoptosis of SK-OV-3 cells
}

\author{
AnLi Zhang ${ }^{1 \dagger}$, Hua Xue ${ }^{1 \dagger}$, XiaoGuang Ling ${ }^{1}$, Yi Gao ${ }^{1}$, Feng Yang ${ }^{1}$, LianSheng Cheng ${ }^{2}$, Jing Liu², Qiang Wu ${ }^{1 *}$
}

\begin{abstract}
Background and Aims: Anti-HER-2 antibodies targeting distinct epitopes have different biological functions on cancer cells. In a previous study, we demonstrated that anti-HER-2 engineering antibody ChA21 was able to bind to subdomain I of HER-2 extracellular domain. In this study, The effects of ChA21 on growth and apoptosis against ovarian carcinoma cell SK-OV-3 over-expressing HER-2 in vitro and in vivo were investigated.

Methods: Cell growth inhibition was evaluated by MTT assay. Apoptosis was detected by TUNEL stain, transmission electron microscopy and flow cytometry on cultured cells and tissue sections from nude mice xenografts. The apoptosis-related proteins Bax and $\mathrm{BCl}-2$ were assessed by immunohistochemistry.

Results: We found that treatment of ChA21 caused a dose-dependent decrease of cell proliferation in vitro and a significant inhibition of tumor growth in vivo. ChA21 therapy led to a significant increase in the induction of apoptosis, and up-regulated the expression of Bax, while the expression of $\mathrm{BCl}-2$ was down-regulated.

Conclusion: These data suggest that ChA21 inhibits the growth and induces apoptosis of SK-OV-3 via regulating the balance between Bax and $\mathrm{BCl}-2$.
\end{abstract}

\section{Introduction}

Ovarian cancer is the most frequent cause of death among all gynecologic cancer patients [1], and there are currently no effective therapeutic approaches for the disease in spite of advances in surgery, chemotherapy, and radiotherapy $[2,3]$. Hence, the effective treatment for ovarian cancer is urgently needed.

HER-2, also named neu/c-erbB-2, is a key member of the epidermal growth factor receptor (EGFR) family, which comprises an extracellular domain (ECD) with four subdomains (I/L1, II/S1, III/L2, and IV/S2), a single transmembrane domain, and an intracellular tyrosine kinase domain $[4,5]$. The aberrant activity of HER-2 has been shown to play a key role in the development and growth of tumor cells [6,7]. HER-2 gene over-expressed in ovarian cancer has been reported to be approximately $15-30 \%[8,9]$. HER-2 over-expression in human carcinoma tissues does relate with the poor prognosis but provide the fundamental rationale for the development of immunotherapy to target HER-2. The most attractive

\footnotetext{
* Correspondence: aydjohn@yahoo.com

† Contributed equally

'Department of Pathology, Anhui Medical University, 69\# Meishan Road, Hefei, Anhui, 230032, PR China
}

humanized antibody against HER-2 is Herceptin [10,11], which blocks HER-2 dimerization and induces apoptosis [12]. It has been used as an agent in first-line treatment of HER-2 over-expressing breast cancer by binding to HER-2 extracellular domain in subdomain IV [13,14]. It was also reported that Herceptin appeared to be a candidate as a treatment modality for HER-2 over-expressing ovarian cancer [15]. ChA21 is an engineered anti-HER-2 antidbody that is prepared by the surface epitope masking (SEM) method, wherein recognized epitopes are mainly located in subdomain I of the HER-2 extracellular domain [16-18].

In previous study, we reported the preparation of an anti-HER-2 monoclonal antibody(MAb) muA21 and found that it could inhibit the growth of the human breast cancer SK-BR-3 cells $[19,20]$. Subsequently, we cloned the genes of variant regions of this monoclonal antibody, constructed the single-chain $\mathrm{Fv}(\mathrm{scFv})$ antibody, and further constructed a chimeric scFv-Fc engineered antibody ChA21 [16]. After that, we constructed a molecular model of Ag-Ab complex based on the crystal structures of the ChA21 scFv and HER-2 ECD, and found that ChA21 recognized epitopes mainly located in subdomain I [18]. In the present study, we hypothesized 
that ChA21 could bring the similarly effects for the growth inhibition of HER-2 over-expressed SK-OV-3 cells and induction of apoptosis as Herceptin binds to subdomain IV.

\section{Materials and methods Cell line}

The HER-2 overexpressing human ovarian cancer cells SK-OV-3 [21] were obtained from the Cell Bank of Shanghai Institutes for Biological Sciences (Shanghai, China). They were cultured in DMEM (Gibco, USA) supplemented with 10\% FBS (Gibco, USA) in an incubator with $5 \% \mathrm{CO}_{2}$ and saturated humidity at $37^{\circ} \mathrm{C}$.

\section{MTT assay}

SK-OV-3 $\left(5 \times 10^{3}\right.$ per well) cells were seeded in 96-well plates and cultured overnight. Then, the medium was replaced with fresh DMEM or the same medium containing ChA21 (prepared as described in previous studies $[16,17]$ ) at concentrations of $0.067,0.2,0.6,1.8$, $5.4 \mu \mathrm{g} / \mathrm{ml}$ for $72 \mathrm{~h}$, or the cells were treated with ChA21 at the concentration of $5.4 \mu \mathrm{g} / \mathrm{ml}$ for $24,48,72,96 \mathrm{~h}$, respectively. MTT (Sigma, USA) with $20 \mu$ l samples was added to each well and incubated for an additional $4 \mathrm{~h}$. Then culture medium was discarded and $150 \mu \mathrm{l}$ dimethyl sulfoxide (DMSO) was added. OD $570 \mathrm{~nm}$ was measured by a multi-well scanning spectrophotometer (Multiskan MK3, Finland). The inhibitory growth rate was calculated as follows: (1 - experimental OD value/ control OD value) $\times 100 \%$.

\section{Inhibition of ChA21 on SK-OV-3 nude mice xenografts}

$\mathrm{BALB} / \mathrm{c}$ female nude mice $(6$ weeks old, $18.0 \pm 2.0 \mathrm{~g}$ ) were obtained from Shanghai Laboratory Animal Center (SLAC, China). SK-OV-3 cells $\left(5 \times 10^{6}\right.$ per mouse) were subcutaneously inoculated into the left flank of the mice. Tumor-bearing mice in which the tumor volume reached about $50 \mathrm{~mm}^{3}$ were selected, and randomized, injected with either sterile normal saline or ChA21 (40 mg/kg) twice weekly via caudal vein (i.v) for 5 weeks. Tumor size was measured twice a week and converted to tumor volume (TV) as the following formula: TV $\left(\mathrm{mm}^{3}\right)=\left(\mathrm{a} \times \mathrm{b}^{2}\right) / 2$, where $\mathrm{a}$ and $\mathrm{b}$ are the largest and smallest diameters (in millimeters), respectively. All animals were killed after giving ChA21 or sterile normal saline for 5 weeks, and the transplantation tumors were removed, weighed and fixed for further study. The tumor inhibition ratio (TIR) was calculated as follows: (1 - experimental mean weight/control mean weight) $\times 100 \%[22]$.

\section{Evaluation of potential adverse effects}

To evaluate the potential side effects or toxicity on mice during treatment of ChA21, gross measures such as weight loss, ruffling of fur, life span, behavior, and feeding were investigated. The tissue of heart, liver, spleen, lung, kidney, and brain were fixed in $10 \%$ neutral buffered formalin solution and embedded in paraffin, and then stained with $H \& E$.

\section{Transmission electron microscopy}

SK-OV-3 cells treated with ChA21 $(5.4 \mu \mathrm{g} / \mathrm{ml})$ for $72 \mathrm{~h}$, as well as $1 \mathrm{~mm} \times 1 \mathrm{~mm}$ tumor tissues from nude mice, were fixed with glutaraldehyde and osmium tetroxide. After dehydration in a graded series of acetone and steeping in propyleneoxide, the samples were ultramicrotomed after embedded in Epon 812. The sections were stained with lead citrate, and examined by an electron microscope (JEM-1230, Japan).

\section{TUNEL staining of apoptotic cells}

SK-OV-3 cells $\left(2.5 \times 10^{4}\right.$ per well $)$ were seeded in 24 well plates with coverslips, and cultured in the medium with $5.4 \mu \mathrm{g} / \mathrm{ml}$ ChA21 for $72 \mathrm{~h}$. Then, the coverslips were taken out, washed, fixed, and stained according to the instruction manual of in situ cell-death detection kits (Roche). The tissue sections from nude mice xenografts were dewaxed and hydrated, and then were incubated with $20 \mu \mathrm{g} / \mathrm{L}$ proteinase $\mathrm{K}$ at room temperature for $15 \mathrm{~min}$, followed by incubation with TUNEL reaction mixture. Converter-peroxidase solution was added for further incubation. Labeled nuclei were demonstrated using 3, 3'-diaminobenzidine and counterstained with hematoxylin. Four equal-sized fields were randomly chosen and analyzed, the apoptotic index (AI) was defined as follows: AI $(\%)=100 \times$ apoptotic cells/total tumor cells.

\section{Propidium iodide staining of dead cells for flow cytometry}

SK-OV-3 cells were incubated with ChA21 (0.2 or $5.4 \mu \mathrm{g} /$ $\mathrm{ml}$ ) for $72 \mathrm{~h}$, harvested and counted, and $1 \times 10^{6}$ cells were resuspended in $100 \mu$ l phosphate-buffered saline (PBS). Then, $5 \mu \mathrm{l}$ of propidium iodide (PI, Beckman, USA) was added, incubated for $30 \mathrm{~min}$ at room temperature in dark. Then the cells were subjected to flow cytometry to measure the death rate (\%) with a Beckman Coulter Epics-XL-MCL cytometer (California, USA).

\section{Immunohistochemical and immunocytochemical staining for $\mathrm{BCl}-2$ and $\mathrm{Bax}$}

The SK-OV-3 cells were cultured and fixed as described above in TUNEL staining. The sections of paraffin-embedded tissue were dewaxed and rehydrated. After inactivating endogenous peroxidase with $3 \% \mathrm{H}_{2} \mathrm{O}_{2}$, and blocking cross-reactivity with normal serum, the sections were incubated overnight at $4{ }^{\circ} \mathrm{C}$ with the Bcl-2 antibody (1:150, Santa Cruz, California, 
USA) and the Bax antibody (1:150, Santa Cruz, California, USA), respectively. Then, the sections were treated with streptoavidin-peroxidase reagent (Zymed, USA), and the peroxidase label was demonstrated using 3, 3'diaminobenzidine, counterstained with hematoxylin. Omission of the primary antibody was used as negative control. The immunostained sections were examined by using an Eclipse E800 microscope (Nikon, Japan) coupled to a digital camera. The mean optical density (MOD) of microscopic images was quantitatively analyzed by Image-pro Plus 5.02 (Media Cybernetics Inc, USA).

\section{Statistical analysis}

Data were expressed as mean \pm standard deviation $(\bar{\chi}$ \pm s). Comparison between groups was made by the
Independent Samples $t$-test, $P<0.05$ was considered statistically significant.

\section{Results}

ChA21 inhibits the growth of SK-OV-3 cells in vitro and in vivo

To evaluate the effect of ChA21 on cell proliferation, human ovarian cancer cells SK-OV-3 were treated with different doses $(0.067-5.4 \mu \mathrm{g} / \mathrm{ml})$ of ChA21 for $72 \mathrm{~h}$ or treated with ChA21 $(5.4 \mu \mathrm{g} / \mathrm{ml})$ for $24,48,72,96 \mathrm{~h}$, respectively. As shown in Fig. 1A, treatment of ChA21 resulted in a dose-dependent inhibition of SK-OV-3 cell proliferation by MTT assay; the growth inhibitory rates were $5.85,10.92,16.55,23.87$ and $35.33 \%$ at the corresponding concentrations of $0.067,0.2,0.6,1.8$ and 5.4 $\mu \mathrm{g} / \mathrm{ml}$, respectively. As shown in Fig. 1B, treatment of

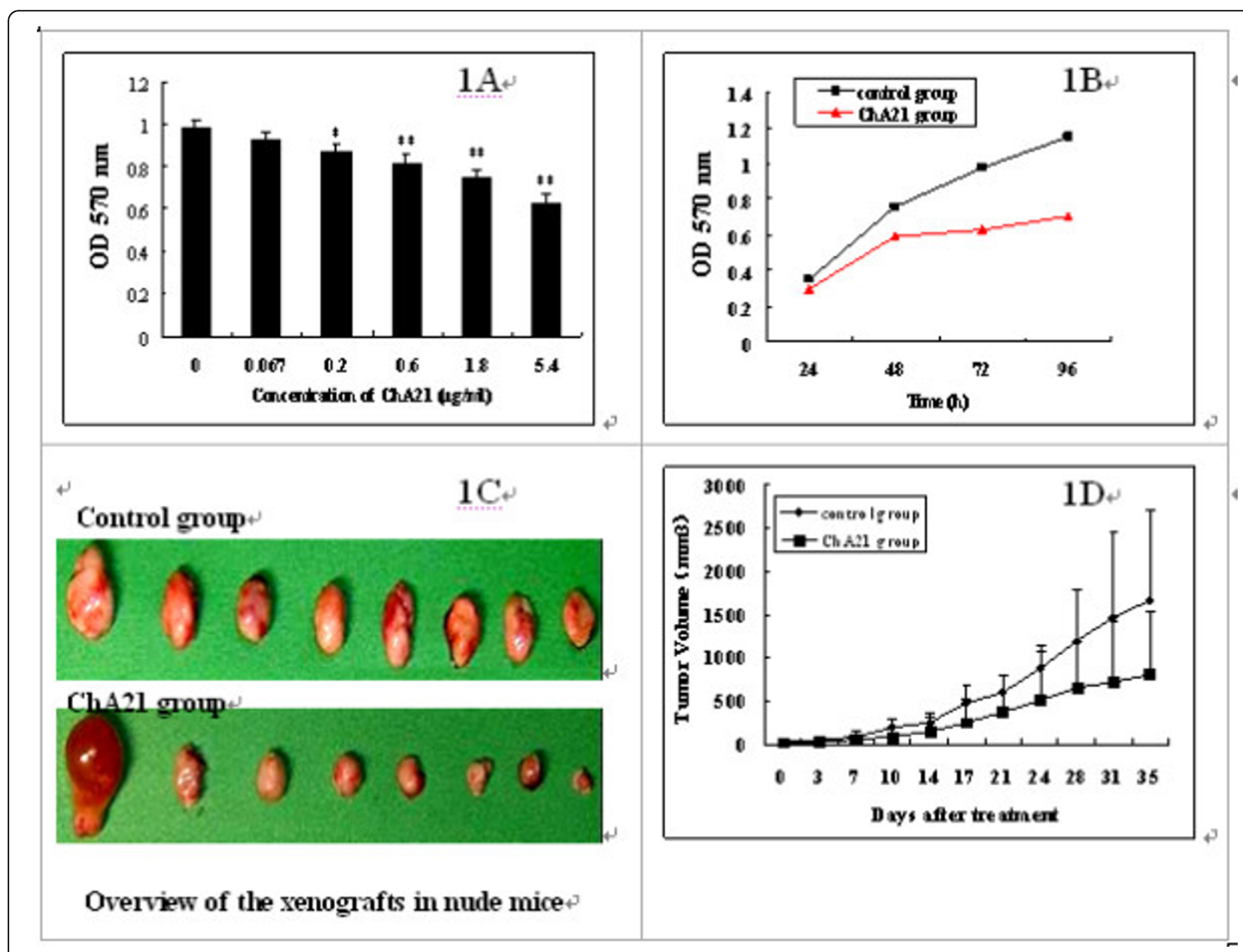

Figure 1 ChA21 inhibits the growth of SK-OV-3 cells in vitro and in vivo. (A) Cells were exposed to $0.067-5.4 \mu \mathrm{g} / \mathrm{ml} \mathrm{ChA21} \mathrm{for} 72 \mathrm{~h}$. (B) Cells were treated with ChA21 at the concentration of $5.4 \mu \mathrm{g} / \mathrm{ml}$ for 24, 48, 72, $96 \mathrm{~h}$, respectively. OD $570 \mathrm{~nm}$ was measured by a multi-well scanning spectrophotometer. Significant differences are represented by asterisk $(P<0.05)$ and double asterisk $(P<0.01)$. (C, D) Female BALB/C nude mice were subcutaneously inoculated with human ovarian cancer cells SK-OV-3 $\left(5 \times 10^{6}\right)$ into the left flank of mice. The mice were randomized and injeceted twice weekly via caudal vein with either sterile normal saline or ChA21 (40 mg/kg) for 5 weeks. Tumor size was measured twice a week and converted to tumor volume. ChA21 treatment group have a significantly reduced tumor volume compared with the controls $(P<0.05)$. Results are representative of the mean \pm s.e.m. of 8 animals in each group. 
ChA21 also resulted in a time-dependent inhibition of SK-OV-3 cells, the growth inhibitory rates were 14.78 , $22.89,34.43$ and $39.85 \%$ at the corresponding times of 24, 48, 72, $96 \mathrm{~h}$.

Female BALB/c nude mice were subcutaneously inoculated with human ovarian cancer cells SK-OV-3 (5 $\times 10^{6}$ ) into the left flank of mice. The mice were randomized and injected twice weekly via caudal vein with either sterile normal saline or ChA21 (40 mg/kg) for 5 weeks. As shown in Fig. $1 C$, D, the tumor volume $\left(\mathrm{mm}^{3}\right)$ in the control group grew remarkably fast, reaching $1664.5 \pm 1028.7$ after 35 days injection. In contrast, the tumor volume $\left(\mathrm{mm}^{3}\right)$ of mice treated with ChA21 was significantly $(P<0.05)$ smaller than the controls, reaching only $813.6 \pm 724.8$. The mean weight $(\mathrm{g})$ of the transplantation tumors in ChA21 treatment group was $0.78 \pm 1.14$, which also significantly $(P<0.05)$ decreased as compared to that in the controls $(1.24 \pm 0.94)$. In addition, the tumor inhibition ratio reached $37.1 \%$.

\section{Observation of Potential Toxicity}

To evaluate the possible adverse effects of the treatments, weight of mice was monitored every 3 days throughout the whole experiment and considered a variable for evaluation of systemic well-being or cachexia. No significant differences in weights were found between the two groups. No adverse consequences in other gross measures such as ruffling of fur, behavior, feeding, or toxic death were observed. In the histopathological examination of the heart, liver, spleen, lung, kidney and brain, no significant injuries were found after 5 weeks injection (data not shown).

\section{ChA21 induces apoptosis of SK-OV-3 cells in vitro and in vivo}

Using transmission electron microscopy, we discerned the ultrastructural changes of SK-OV-3 cells induced by ChA21. After treatment of ChA21 $(5.4 \mu \mathrm{g} / \mathrm{ml})$ for $72 \mathrm{~h}$ or the tumor tissues removed from nude mice treated ChA21 (40 mg/kg) for 5 weeks, a large number of cells presented a series of ultrastructural changes such as chromatin condensation, chromatin crescent, and nucleus fragmentation (Fig. 2B, D), all of which were characteristics of cells undergoing apoptosis. On the contrary, control cells were morphologically normal and exhibited no signals of apoptosis (Fig. 2A, C).

Cells cultured on coverslips and tissue sections from the above experiments were stained with the TUNEL agent, and examined by microscopy. Less apoptotic cells were detected in the control group, whereas more apoptotic cells were detected in ChA21 treatment group (Fig. 3 ). The apoptotic cells on coverslips and tissue sections were counted to calculate the apoptotic index. In vitro, the AI value in ChA21 $(5.4 \mu \mathrm{g} / \mathrm{ml})$ treatment group

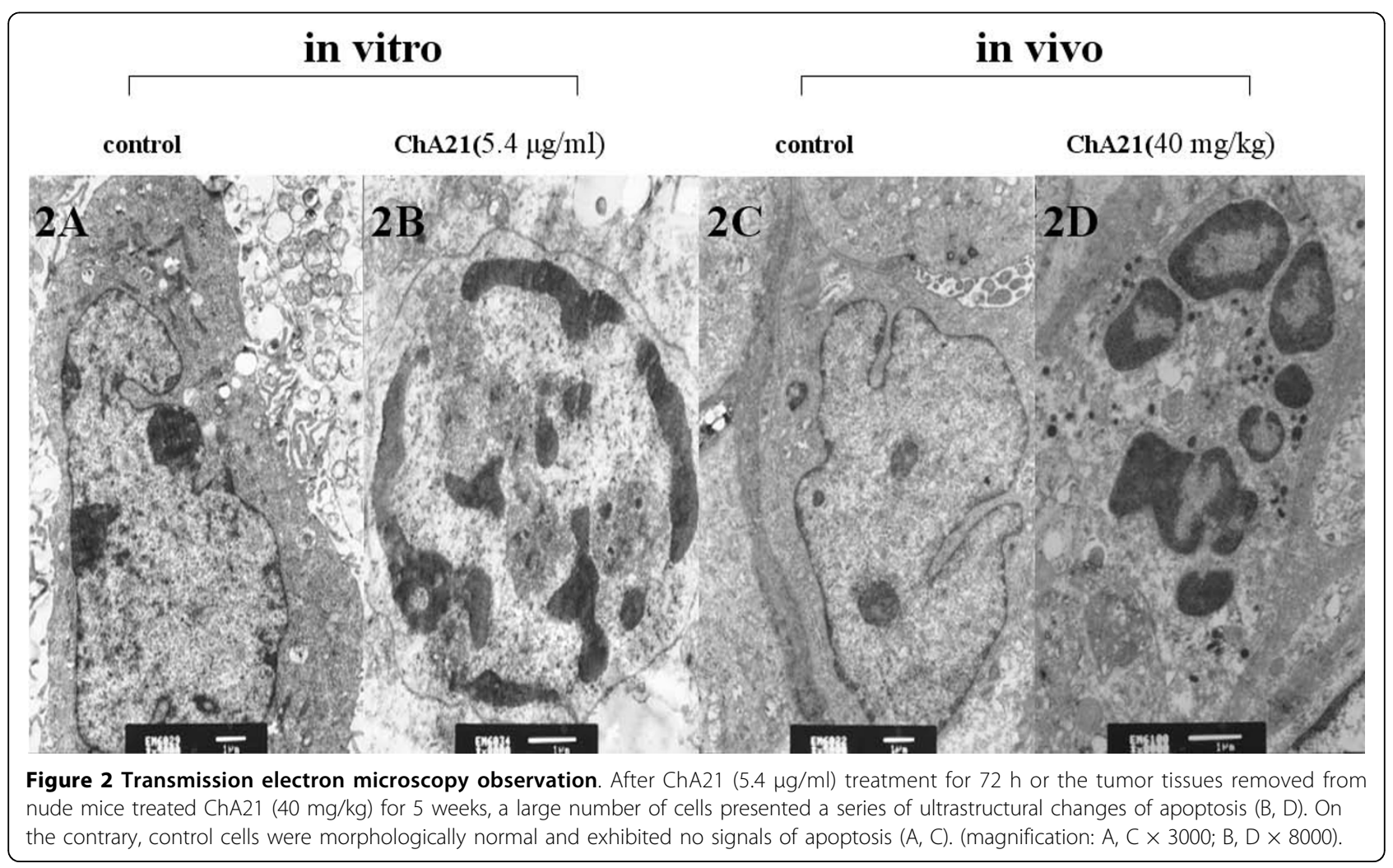




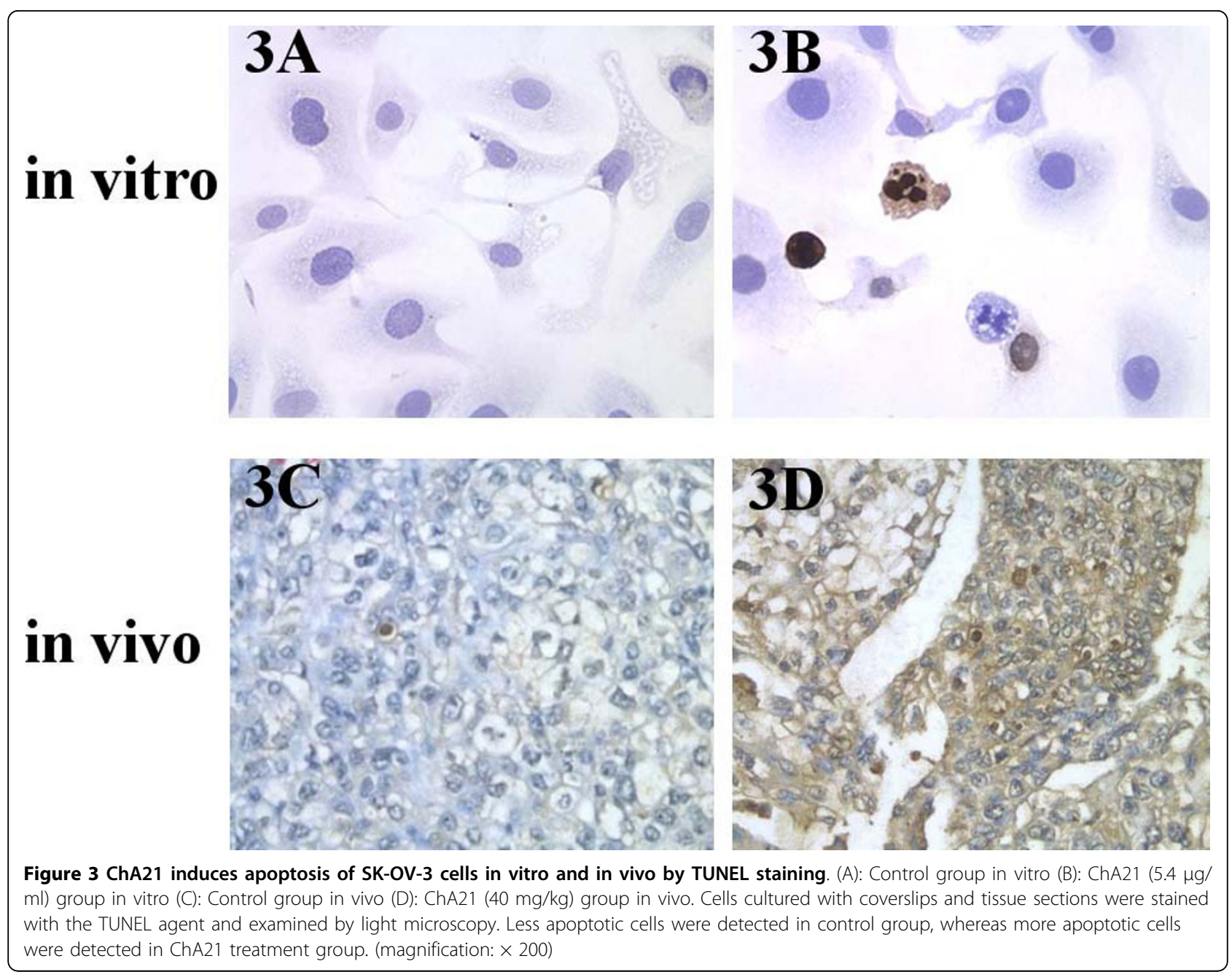

reached $16.22 \pm 1.05$, which was higher than that in the controls $(6.22 \pm 1.09, P<0.05)$. In vivo, the AI value in ChA21 $(40 \mathrm{mg} / \mathrm{kg})$ treatment group reached $9.16 \pm 2.44$, which was also higher than that in the controls $(3.45 \pm$ $0.98, P<0.05)$.

SK-OV-3 cells were incubated with ChA21 (0.2 or 5.4 $\mu \mathrm{g} / \mathrm{ml}$ ) for $72 \mathrm{~h}$, and flow cytometric analysis was used to measure the death rate. As shown in Fig. 4, there was a significant difference between ChA21 group and control group in the death rate $(\%)(P<0.05)$. After the treatment of SK-OV-3 cells with ChA21 $(0.2$ or $5.4 \mu \mathrm{g} /$ $\mathrm{ml}$ ) for $72 \mathrm{~h}$, the death rate (\%) reached $8.75 \pm 0.97$, and $19.73 \pm 1.99$, respectively.

\section{Expression of Bcl-2 and Bax}

Detection of the expression of apoptosis-related proteins of Bcl-2 and Bax by immunohistochemistry showed that ChA21 therapy could up-regulate the expression of Bax, and down-regulate the expression of Bcl-2 (Fig. 5), thereby reducing the ratio of $\mathrm{Bcl}-2 / \mathrm{Bax}$ in vitro and in vivo. As shown in Fig. 6, MOD values of Bax in ChA21 group were higher than those in control group $(P<$ $0.05)$, while MOD values of $\mathrm{Bcl}-2$ and the ratio of $\mathrm{Bcl}-2$ to Bax were lower $(P<0.05)$ both in vitro and in vivo.

\section{Discussion}

In recent years, a number of monoclonal antibodies (MAb) have been developed against HER-2 ECD, such as 4D5 (Herceptin, trastuzumab) and 2C4 (Pertuzumab) $[10,23]$. Herceptin is a humanized recombinant MAb that was first approved by the U.S. FDA for use in HER2 over-expressing metastatic breast cancer. Current studies show that it appears to be a candidate as a treatment modality for HER-2 over-expressing ovarian cancer as well [24]. However, more studies in clinical application showed that there is an increased incidence of serious cardiac events, particularly when Herceptin was administered in combination with anthracyclines $[25,26]$, and pulmonary complications also had been reported [27]. Patients who have had a significant 


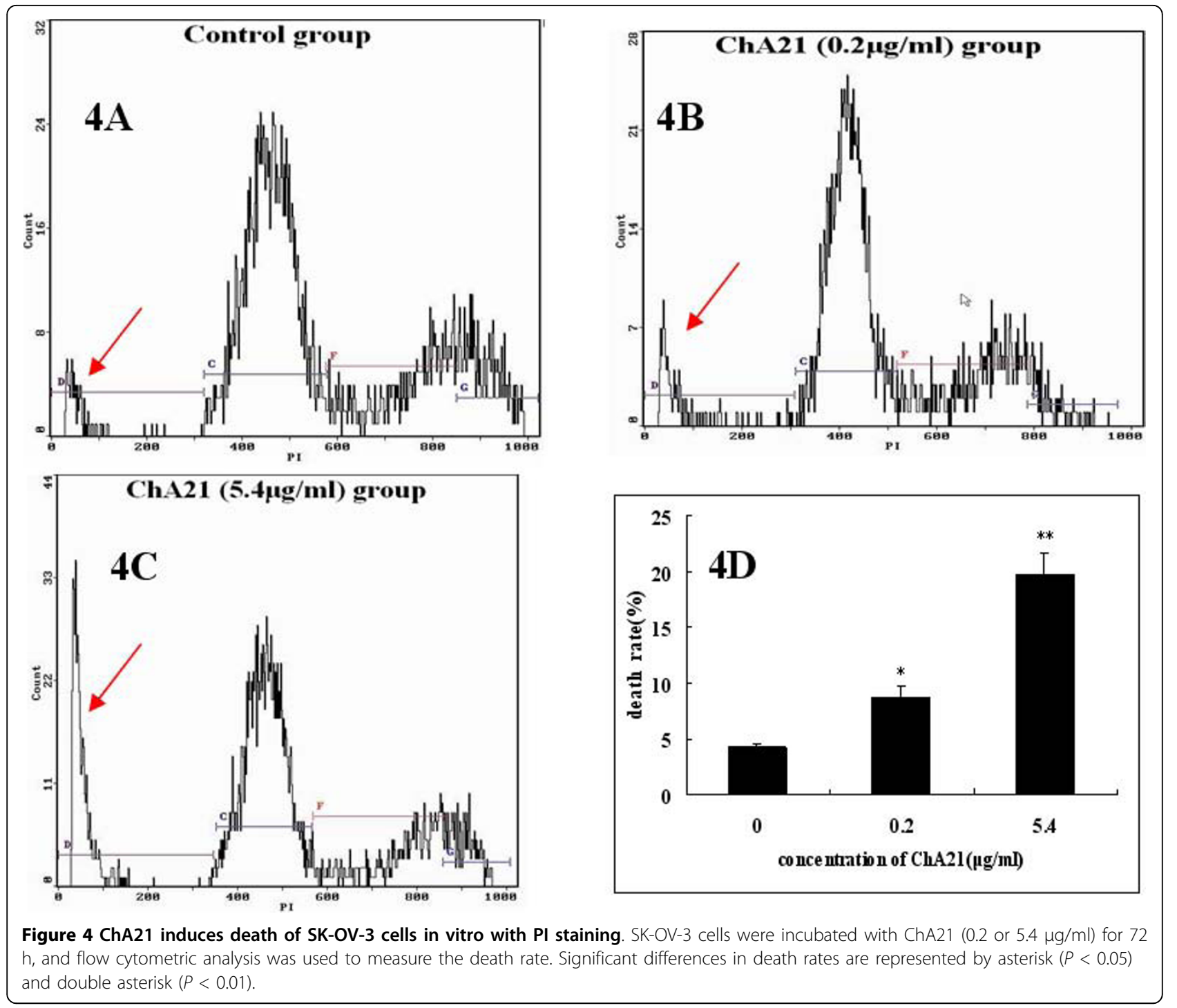

therapeutic effect for a time by Herceptin treatment started to appear the drug resistant [28,29]. Moreover, according to the surveyed data about the clinical therapeutic effect of Herceptin, the therapeutic effective rate of Herceptin treated alone to patients with HER-2 overexpressed only reached $12-14 \%$ [30]. These results urge people to conduct more researches, regarding the mechanism of antibodies curing the neoplasms, and develop novel humanized recombinant MAb for HER-2.

Therefore, three strains of murine MAb A18, A21, and A22, which direct against HER-2 ECD were developed, and MAb A21 was found to specifically inhibit the growth of HER-2 over-expressing cells [20]. To reduce the potential for generating a human anti-mouse immune response, Murine MAb A21 was humanized to develop an anti-HER-2 engineering antidbody, ChA21 $[16,17]$. In previous study, we constructed a molecular model of Ag-Ab complex based on the crystal structures of the ChA21 scFv and HER-2 ECD [18]. Unlike Herceptin that binds to subdomain IV, ChA21 recognizes epitopes that are mainly located in subdomain I. It is possible, that anti-HER-2 antibodies targeting distinct epitopes have different biological functions on cancer cells with different mechanisms [31].

Thus, in the present study, we confirmed that ChA21 binding to subdomain I could inhibit the growth and induce apoptosis of HER-2 over-expressing human ovarian cancer cells SK-OV-3 in vitro and in vivo. The results showed that in vitro, the cell growth was significantly inhibited by ChA21 in a dose- and time-dependent manner. Likewise, ChA21 (40 mg/kg) inhibited the growth of SK-OV-3 cells in vivo with the tumor inhibition ratio of $37.1 \%$. It is known that apoptosis is the programmed death of cells, a variety of studies have 


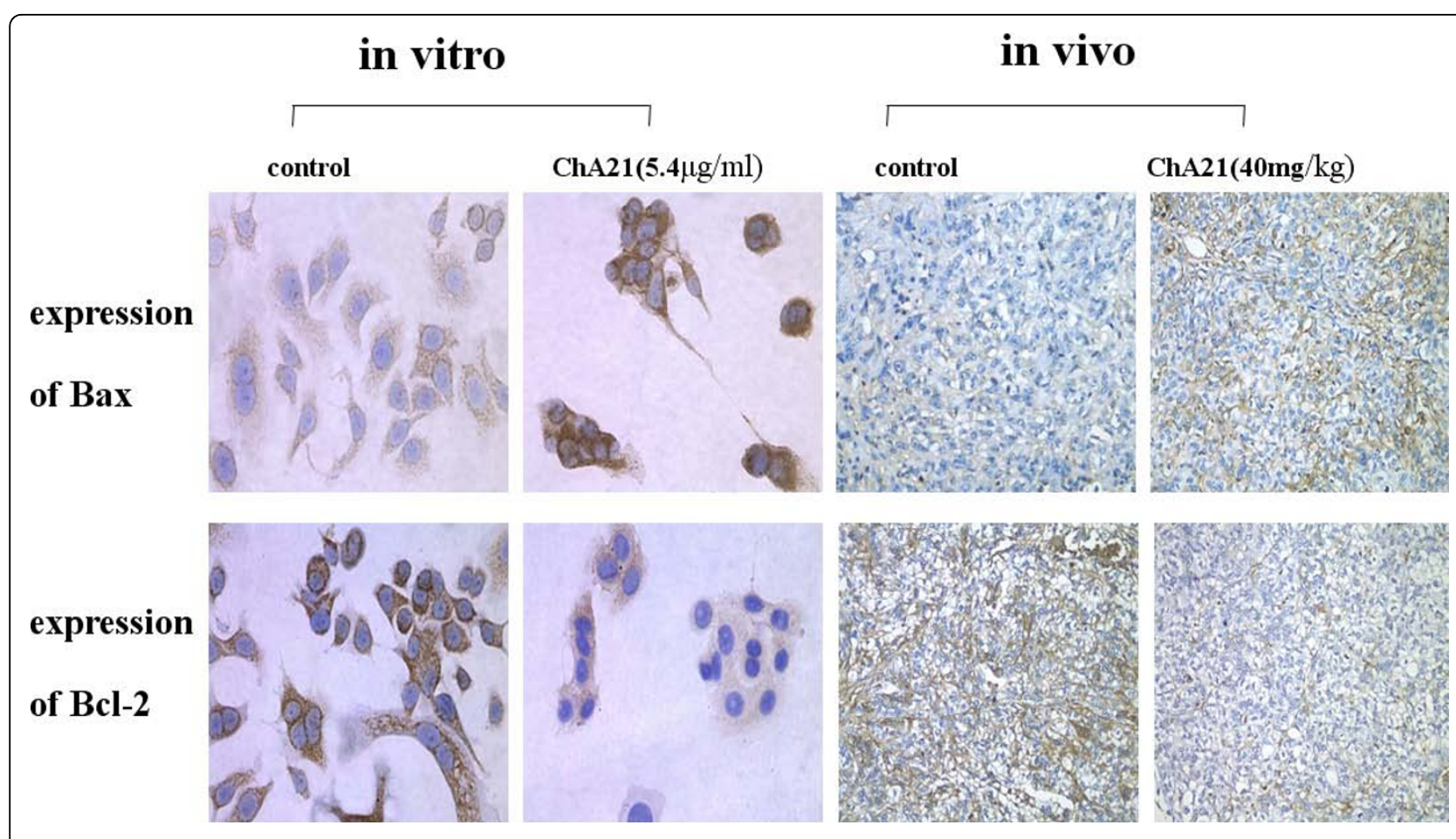

Figure 5 Expression of Bcl-2 and Bax as detected by immunohistochemistry. Detection of the expression of apoptosis-related proteins of $\mathrm{BCl}-2$ and Bax showed that ChA21 therapy could upregulate the expression of Bax and downregulate the expression of $\mathrm{BCl}-2$ in vitro and in vivo.
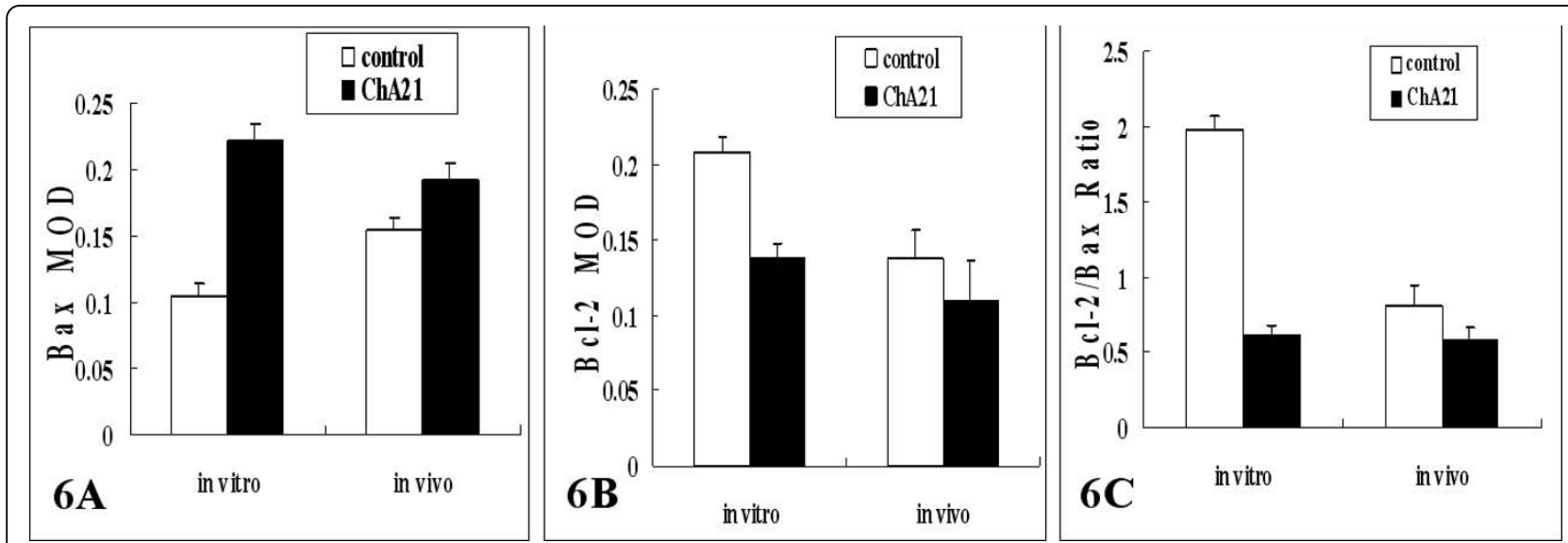

Figure 6 The MOD values on expression of $\mathbf{B c l}-2$ and Bax. MOD values of Bax in ChA21 treatment group were higher than those in the control group $(P<0.05)$, while MOD values of $\mathrm{BCl}-2$ and the ratio of $\mathrm{BCl}-2$ to Bax were lower $(P<0.05)$ both in vitro and in vivo. (magnification: in vitro $\times 400$; in vivo $\times 200$ ).

revealed that the uncontrolled growth of neoplasms is not only the cause of the over growth but also the loss of natural apoptosis [32,33]. Therefore, the antibody that is capable of inducing cancer cells apoptosis would be helpful for cancer treatment. In this study, transmission electron microscope, TUNEL staining and flow cytometry were used to detect apoptosis, and the results demonstrated that ChA21 could induce apoptosis on SK-OV-3 cells both in vitro and in vivo. Hence, we can deduce that the growth inhibition of ChA21 on SK-OV3 cells was at least partially contributed by its role of apoptosis induction. To further investigate the possible molecular mechanism of apoptosis induced by ChA21, apoptosis-regulated proteins $\mathrm{Bcl}-2$ and $\mathrm{Bax}$ were detected by immunocytochemistry and immunohistochemistry. It is known that $\mathrm{Bcl}-2$ gene acts to inhibit apoptosis, while Bax gene induces apoptosis. The imbalanced expression of $\mathrm{Bcl}-2$ to Bax protein influences the 
apoptosis of cells stimulated by either external or internal factors [34,35]. Recent studies reported that HER-2 over-expression is accompanied by up-regulation of Bcl2 and down-regulation of Bax [36,37]. Our results showed that after exposure to ChA21, Bcl-2 expression of SK-OV-3 cells was decreased, and Bax expression was increased, resulting in a decrease in Bcl-2/Bax value. Therefore, we concluded that one of the pathways of ChA21 inducing apoptosis might up-regulate Bax expression, and down-regulate Bcl-2 expression.

In conclusion, the results indicate that ChA21 could inhibit growth and induce apoptosis of human ovarian cancer cell line SK-OV-3 via regulating the balance between Bax and Bcl-2. It suggests that ChA21 might be a new promising candidate in the treatment of HER-2 over-expressed ovarian cancers. In addition, the mechanisms of ChA21 inhibits SK-OV-3 cells growth not only via inducing apoptosis, but also by interfering with HER-2 heterodimerization and affecting HER-2 signaling pathway, and further study is needed.

\section{Acknowledgements}

This work was supported by the National High Technology Program of China ("863 project", No. 2004AA215260) and Anhui Province Nature Science Foundation (No. 03043701) and National Science Foundation of China (30873047).

\section{Author details}

'Department of Pathology, Anhui Medical University, 69\# Meishan Road, Hefei, Anhui, 230032, PR China. ${ }^{2}$ School of Life Science, University of Science and Technology of China, Hefei, 230027, PR China.

\section{Authors' contributions}

ZAL carried out the animal experiment, $\mathrm{XH}$ carried out the cells experiment, WQ participated in the design of the study. LXG carried out the transmission electron microscopy observation. YF carried out the immunohistochemical staining. YG participated in the study design. CL carried out the data collection. $L J$ carried out the design of the study. All authors read and approved the final manuscript.

\section{Competing interests}

The authors declare that they have no competing interests.

Received: 28 December 2009 Accepted: 10 March 2010 Published: 10 March 2010

\section{References}

1. Jemal A, Siegel R, Ward E, et al: Cancer statistics. Cancer Journal for Clinicians 2008, 58:71-96.

2. Breedlove G, Busenhart C: Screening and detection of ovarian cancer. Journal of Midwifery \& Women's Health 2005, 50:51-54.

3. Bast RC, Hennessy B, Mills GB: The biology of ovarian cancer: new opportunities for translation. Nature Reviews Cancer 2009, 9:415-428.

4. Carpenter G: Receptors for epidermal growth factor and other polypeptide mitogens. Annu Rev Biochem 1987, 56:881-914.

5. Coussens $L$, Yang-Feng TL, Liao YC, et al: Tyrosine kinase receptor with extensive homology to EGF receptor shares chromosomal location with neu oncogene. Science 1985, 230:1132-1139.

6. Popescu NC, King CR, Kraus MH: Localization of the human erbB-2 gene on normal and rearranged chromosomes 17 to bands q12-21.32. Genomics 1989, 4:362-366.

7. Yarden Y, Sliwkowski MX: Untangling the ErbB signalling network. Nat Rev Mol Cell Biol 2001, 2:127-137.
8. Slamon DJ, Godolphin W, Jones LA: Studies of the HER-2/neu protooncogene in human breast and ovarian cancer. Science 1989, 244:707-712.

9. Verri E, Guglielmini P, Puntoni M: HER2/neu oncoprotein overexpression in epithelial ovarian cancer: evaluation of its prevalence and prognostic significance. Oncology 2005, 68:154-161.

10. Cheng JD, Rieger PT, von Mehren M: Recent advances in immunotherapy and monoclonal antibody treatment of cancer. Semin Oncol Nurs 2000, 16:2-12.

11. Bell Richard: What Can We Learn from Herceptin Trials in Metastatic Breast Cancer? Oncology 2002, 63:39-46.

12. Cuello Mauricio, Seth A, Ettenberg, Amy S, et al: Down-Regulation of the erbB-2 Receptor by Trastuzumab (Herceptin) Enhances Tumor Necrosis Factor-related Apoptosis-inducing Ligand-mediated Apoptosis in Breast and Ovarian Cancer Cell Lines that Overexpress erbB-2. Cancer Res 2001, 61:4892-900.

13. Cho HS, Mason K, Ramyar KX, et al: Structure of the extracellular region of HER2 alone and in complex with the Herceptin Fab. Nature 2003, 421:756-760.

14. Fujimura M, Katsumata N, Tsuda $H$, et al: HER2 Is Frequently Overexpressed in Ovarian Clear Cell Adenocarcinoma: Possible Novel Treatment Modality Using Recombinant Monoclonal Antibody against HER2, Trastuzumab. Jpn J Cancer Res 2002, 93:1250-1257.

15. Dean-Colomb W, Esteva FJ: Her2-positive breast cancer: herceptin and beyond. Eur J Cancer 2008, 44:2806-2812.

16. Cheng LS, Liu AP, Yang JH: Construction, expression and characterization of the engineered antibody against tumor surface antigen, p185(c-erbB2). Cell Res 2003, 13:35-48.

17. Wang Jing, Shi Yu, Liu Yanqi: Purification and characterization of a singlechain chimeric anti-p185 antibody expressed by CHO-GS system. Protein expression and purification 2005, 41:68-76.

18. Hu S, Zhu Z, Li L, et al: Epitope mapping and structural analysis of an anti-ErbB2 antibody A21: Molecular basis for tumor inhibitory mechanism. Proteins 2008, 70:938-949.

19. Wang C, Li Y, Li P: Generation and Characterization of monoclonal antibodies specific for the oncogene product $\mathrm{P} 185^{\text {neu/c-erbB-2 }}$ by surface epitope masking (SEM). J Chin Immunol 2000, 16:539-541.

20. Ping LI, Yun $\mathrm{LI}$, Chen Wang: Investigation on the anti-cancer activities of anti-p185 monoclonal antibodies in vitro. Chin Immunol 2002, 18:33-35.

21. Steffen AC, Göstring L, Tolmachev V, et al: Differences in radiosensitivity between three HER2 overexpressing cell lines. Eur J Nucl Med Mol I 2008, 35:1179-1191.

22. Sujun $L$, Xun $L$, Daxu $L$, et al: Tumor inhibition and improved immunity in mice treated with flavone from Cirsium japonicum DC. International Immunopharmacology 2006, 6:1387-1393.

23. Jackson JG, St Clair P, Sliwkowski MX, et al: Blockade of epidermal growth factor- or heregulin-dependent ErbB2 activation with the anti-ErbB2 monoclonal antibody $2 \mathrm{C} 4$ has divergent downstream signaling and growth effects. Cancer Res 2004, 64:2601-2609.

24. Vogel CL, Cobleigh MA, Tripathy D, et al: Efficacy and safety of trastuzumab as a single agent in first-line treatment of HER2overexpressing metastatic breast cancer. J Clin Oncol 2002, 18:719-726

25. Perez EA: Cardiac toxicity of ErbB2-targeted therapies: what do we know? Clin Breast Cancer 2008, 8:114-120.

26. Hattori K, Nishi Y, Nakamura S: Evaluation of cardiac dysfunction after herceptin treatment in patients with metastatic breast cancer by echocardiography. Rinsho Byori 2007, 55:120-125.

27. Vahid B, Marik PE: Pulmonary complications of novel antineoplastic agents for solid tumors. Chest 2008, 133:528-538.

28. Slamon DJ, Leyland-Jones B, et al: Use of chemotherapy plus a monoclonal antibody against HER2 for metastatic breast cancer that overexpresses HER2. N Engl J Med 2001, 344:783-792.

29. Calabrich A, Fernandes Gdos S, Katz A: Trastuzumab: mechanisms of resistance and therapeutic opportunities. Oncology (Williston Park) 2008, 22:1250-1258

30. Chen MH: Cardiac dysfunction induced by novel targeted anticancer therapy: an emerging issue. Curr Cardiol Rep 2009, 11:167-174.

31. Wang JN, Feng JN, Yua M: Structural analysis of the epitopes on erbB2 interacted with inhibitory or non-inhibitor monoclonal antibodies. Mol Immu nol 2004, 40:963-969. 
32. Tortora G, di Isernia G, Sandomenico C, et al: Synergistic inhibition of growth and induction of apoptosis by 8-chloro-cAMP and paclitaxel or cisplatin in human cancer cells. Cancer Res 1997, 57:5107-5111.

33. Cummings MC, Winterford CM, Walker NL: Apoptosis. Am J Surg Pathol 1997, 21:88-101.

34. Gillardon F, Wickert H, Zimmermann M: Up-regulation of bax and downregulation of bcl-2 is associated with kainate-induced apoptosis in mouse brain. Neurosci Lett 1995, 192:85-88.

35. Adams JM, Cory S: The bcl-2 protein family: arbiters of cell surival. Science 1998, 281:1322-1326

36. Rakesh $\mathrm{K}$, Mahitosh M, Allan $\mathrm{L}$, et al: Overexpression of HER2 Modulates $\mathrm{BCl}-2, \mathrm{BCl}-\mathrm{XL}$, and Tamoxifen-induced Apoptosis in Human MCF-7 Breast Cancer Cells. Clin Cancer Res 1996, 2:1215-1219.

37. Zheng L, Weiya X, BingLiang F, et al: Targeting HER-2/neu-overexpressing breast cancer cells by an antisense iron responsive element-directed gene expression. Cancer lett 2001, 174:151-158.

doi:10.1186/1756-9966-29-23

Cite this article as: Zhang et al:: Anti-HER-2 engineering antibody

ChA21 inhibits growth and induces apoptosis of SK-OV-3 cells. Journal of Experimental \& Clinical Cancer Research 2010 29:23.

\section{Submit your next manuscript to BioMed Central} and take full advantage of:

- Convenient online submission

- Thorough peer review

- No space constraints or color figure charges

- Immediate publication on acceptance

- Inclusion in PubMed, CAS, Scopus and Google Scholar

- Research which is freely available for redistribution

Submit your manuscript at www.biomedcentral.com/submit 